\title{
Ocupação cabocla e extrativismo madeireiro no alto capim: uma estratégia de reprodução camponesa.
}

\author{
Gabriel MEDINA ${ }^{1}$
}

\begin{abstract}
RESUMO
Com o avanço da atividade madeireira através da Bacia Amazônica, comunidades localizadas ao longo das fronteiras madeireiras passam a ter oportunidade de vender os direitos de extração da madeira de suas áreas. O valor localmente percebido e as decisões das populações locais sobre a forma de uso de seus recursos contrastam fortemente com as visões globalmente construídas sobre o valor da floresta tropical. Este valor local é baseado em representações que consideram a importância local dos produtos florestais e no contexto em que estas representações são construídas. Para explorar esta temática, o artigo começa com uma reconstrução do histórico de uma comunidade cabocla enfocando nas dinâmicas de uso da floresta. Para os comunitários, a madeira sempre representou uma herança que poderia ser gasta ao longo do tempo. A madeira foi o principal produto da floresta com valor de mercado e, até recentemente, sua extração não reduziu significativamente o acesso aos outros produtos florestais. A madeira, então, foi vista como uma berança com valor de troca e uso não conflituoso. Quatro fatores sócio-econômicos influenciaram a continuidade das vendas de madeira mesmo quando as perdas no consumo de produtos não madeireiros ficaram evidentes: 1) relações paternalistas entre os compradores da madeira e os caboclos; 2) dificuldades de gestão comum dos recursos; 3) especialização na extração de madeira e dependência de produtos externos e; 4) crescente envolvimento no mercado que demandou maior quantidade de dinheiro para suprir novas necessidades.
\end{abstract}

\section{PALAVRAS-CHAVE}

extrativismo, produtos florestais não madeireiros (PFNM), caboclo, desmatamento, Amazônia.

\section{Caboclo occupation and timber extractivism at upper Capim river: a peasant reproduction strategy.}

\begin{abstract}
As the timber industry advances throughout the Amazon basin, communities located along logging frontiers are increasingly approached to sell the rights to their timber. Such communities consider several aspects to assess the value of forest products. Locally perceived value and behaviors towards tropical forest resources contrast sharply with globally constructed views of tropical forest value. This locally perceived value is based on representations regarding the importance of forest products and on the context in which these representations are formed. To explore this theme, the paper begins with a bistorical reconstruction of a caboclo community focusing on forest resource use and dynamics during the last hundred years. For the households within the study communities, timber always represented a natural beritage that could be spent over time. It was the principal product with market value and, during initial timber sales, extraction did not significantly reduce access to other forest products. Therefore, timber resources represented an inheritance with exchange value and little conflicting use. Four socioeconomic factors were identified which influenced communities to sell timber despite the losses in non-timber forest products that they began to experience over time: 1) paternalistic relationships among buyers and caboclos; 2) difficulties in common property resource management; 3) quick cash gained from timber sales guaranteed access to market products and; 4) expanding market involvement required increased cash to meet increasing needs.
\end{abstract}

KEY WORDS

extractivism, non-timber forest products (NTFP), native, deforestation, Amazonia.

\footnotetext{
${ }^{1}$ Licenciado Pleno em Ciências Agrárias, MSc., Consultor do Centro para a Pesquisa Florestal Internacional (CIFOR). Endereço: Convênio Embrapa/ CIFOR, Tv. Enéas Pinheiro s/n, Belém, Pará. CEP. 66.095-100. E-mail: g.medina@cgiar.org
} 


\section{ACTA \\ AMAZONICA}

OCUPAC̄̃̃ CABOCLA E EXTRATIVISMO MADEIREIRO

NO ALTO CAPIM: UMA ESTRATÉGIA DE REPRODUÇÃO CAMPONESA

\section{INTRODUÇÃO}

Raramente mencionado, um dos grandes impactos da construção de rodovias através da Amazônia brasileira é o crescente contato entre empreendimentos grandes e modernos e pequenas comunidades rurais remotas. Assim que as rodovias permitem que fazendeiros e madeireiros penetrem em áreas antes inacessíveis para eles, comunidades caboclas rapidamente se descobrem vivendo entre novos e poderosos vizinhos.

Em seu processo de expansão na Amazônia, a atividade madeireira tem implantado um modelo de grande crescimento econômico inicial seguido de um rápido colapso (Veríssimo et al., 2002), que tem levado a uma tendência constante de migração para novas fronteiras (Schneider et al., 2000). O rápido crescimento da indústria madeireira tem sido garantido, em parte, pelo sucesso dos madeireiros em convencer pequenas comunidades, a vender os direitos de exploração de sua floresta para a extração de madeira.

Para comunidades que se encontram em fronteiras de expansão da atividade madeireira e ainda possuem áreas de floresta - geralmente com grande valor para sua subsistência, mas onde também se encontram madeiras de alto valor comercial - a questão do valor dos produtos florestais se impõe constantemente. Diante de freqüentes opções pela venda da madeira, torna-se imperativo indagar: por que comunidades com áreas de floresta optam pela exploração da madeira com ganhos limitados ao momento da venda, enquanto que o aproveitamento dos Produtos Florestais Não Madeireiros (PFNM) poderia se dar por tempo indeterminado?

Considerando a discrepância entre a ênfase global à alternativa sustentável do extrativismo de PFNM e as escolhas econômicas das comunidades, torna-se essencial avaliar o significado do valor da floresta a partir da perspectiva local. A valorização dos recursos florestais pelas comunidades é resultado de representações feitas sobre a importância da floresta e do contexto em que tais representações são construídas. Como mostra Godelier (1984), a relação do homem com a natureza implica na elaboração de representações e interpretações compartilhadas pelos membros da sociedade. Segundo o autor, as diferentes formas de intervenção individual e coletiva sobre a natureza são baseadas nestas representações e interpretações. Estas representações, por sua vez, são fortemente influenciadas pelo contexto em que acontecem. Segundo Luckert e Campbell (2002:230) "os valores que as pessoas atribuem para os recursos florestais são chaves para compreender a racionalidade de suas decisões". É neste sentido que muitos moradores da floresta podem estar prontos para convertê-la para outros usos, mesmo considerando sua importância, se a opção está dentro de seu alcance e se as circunstâncias os levam a isto (Henkemans, 2001).

Para explorar esta temática, este trabalho foi desenvolvido a partir da reconstrução do histórico de uma comunidade cabocla e da forma como ela se apropriou de seus recursos florestais. A comunidade estudada, comunidade do Quiandeua, pertence ao município de Ipixuna-do-Pará e localiza-se às margens do Rio Capim. Na comunidade moram, hoje, 206 pessoas, das quais 118 são homens e 88 são mulheres. É um grupo composto essencialmente por negros, constituído depois de diversas etapas de migração de famílias que residiram antes em áreas do Baixo Capim e seus afluentes. São 32 famílias vivendo ao longo dos aproximadamente 2.300 hectares pertencentes à comunidade. A área não possui divisão de lotes - é de propriedade comum.

Este trabalho está dividido em três partes. Primeiro, cuida-se do histórico distante do grupo, desde sua chegada, quando desenvolveu o extrativismo da madeira em prancha, até o período em que começa a trabalhar tirando madeira em rolos para vender para serrarias que se estabeleceram nas proximidades. Depois, retrata-se a chegada das empresas madeireiras que passam a comprar os direitos de exploração da madeira em tora da área da comunidade. Na terceira parte é discutida a representação feita sobre os recursos florestais e os fatores contextuais que aí exerceram influência.

\section{Metodologia da coleta de dados}

Como neste trabalho o interesse é pelo valor atribuído aos recursos florestais pelos comunitários, o esforço metodológico esteve centrado em buscá-lo nos discursos dos membros da comunidade. Para ter acesso a estes discursos, a opção adotada foi a de reconstruir o histórico de apropriação dos recursos florestais pela comunidade e, a partir das construções feitas pelos entrevistados, buscar compreender a representação da importância destes recursos e o contexto em que foi construída.

O levantamento do histórico se desenvolveu através de contatos realizados em cinco viagens de campo, ao longo de 2001 e 2002, que compreenderam, no total, 45 dias de convivência com a comunidade. Para a reconstrução do histórico, as entrevistas se deram de forma semi-estruturadas buscando associar a casualidade e a liberdade das conversas com a necessidade de se percorrer um roteiro préestabelecido, contendo questões essenciais para a construção do trabalho. Para iniciar as entrevistas foram utilizadas perguntas abertas do tipo: me conte como era a vida aqui quando a senhora se casou? A partir, daí perguntas mais específicas, do tipo: o que foi feito com o dinheiro recebido pela venda da madeira deste período?, foram priorizadas buscando aprofundar temáticas que pudessem ser de interesse do interlocutor.

\section{Parte 1 - de 1920 a 1985 - Madeira Branca das Margens dos Rios e Igarapés}

\section{De 1920 a 1935 - Os Chegantes}

Entre 1897 e 1911 Belém vivenciou uma série de reformas urbanas patrocinadas pelo boom da borracha. A cidade precisava ser saneada e reorganizar seu espaço para 


\section{ACTA AMAZONICA}

suportar o crescimento demográfico e se preparar para o futuro (Derenji, 1994). A capital do Pará e as cidades próximas construíam, e a demanda por madeira era grande.

O Rio Capim tem uma corrente muito forte e deságua no Rio Guamá, próximo a Belém. Isto o tornava uma das fontes imediatas da madeira utilizada para as construções neste período. No entanto, a madeira mais acessível, aquela próxima aos rios e igarapés, de onde saia boiando, já não era mais encontrada com facilidade no Baixo Capim. Começava, então, o processo de ocupação e extração madeireira no Alto Capim. ${ }^{2}$

A história do grupo de que trata este estudo começa quando, na década de 1920, Salazar, um caboclo vindo de Avencar (Baixo Capim), se estabeleceu na área que hoje é da comunidade do Quiandeua, como entreposto comercial para extratores de madeira branca que subiam o rio .

Os caboclos mais velhos ainda têm muito vivas as lembranças do patrimônio erguido ali por Salazar. As entrevistas mostram que tudo foi constituído à custa de muito trabalho, de boas relações com o "patrão" que lhe aviava as mercadorias para sua cantina e do aviamento de extratores locais de madeira. O comerciante do Quiandeua fornecia o rancho necessário para os "serradores de serrotão" " que subiam o rio durante 10 a 15 dias de "casco de remo de faia" ${ }^{4}$ e ficavam de cinco a seis meses no Alto para voltar com dúzias e dúzias de pranchas serradas de madeira branca, principalmente de virola (Virola sp.; no Capim conhecida como envirola), marupá (Simarouba amara), freijó (Cordia sp.) e faveira (Parkya sp.). O próprio Salazar tirava pouca madeira; o comércio e os plantios eram suas principais atividades.

Para as famílias que moravam no Alto, as dificuldades de acesso aos centros urbanos eram grandes. Comprava-se pouco, mas era preciso comprar aquilo que não se produzia: o rancho era sabão; para roupa, compravam "o corte"; para a agricultura, terçado, machado e enxada; o sal era distribuído pelo governo em barras que eram trituradas e a carne invariavelmente vinha da caça abundante e dos peixes. Os filhos desta época ainda contam que o açúcar para adoçar o café era obtido da garapa da cana "cortada de manhã bem cedinho"; o azeite para as lamparinas, embora comprado por muitos, algumas vezes era produzido a partir de uma planta chamada carrapatinho. Para fazer fogo, usavam "uma isca (tipo espuma de colchão) que dá no 'pau-de-isca', é um pau amarelo. Eles (os antigos) enrolavam em uma pedrinha, tipo pedra de isqueiro (que era comprada) e batiam, tá!" (Beca, homem com 44 anos).

Depois da morte de Salazar, no começo da década de 1930, é que os homens que moravam no Quiandeua começaram a subir o rio com maior intensidade e a exploração de madeira serrada se tornou a atividade mais importante para o sustento das famílias. No Alto, com o desenvolvimento do comércio de madeira, começaram a chegar novas famílias que, em geral, foram se estabelecendo individualmente nas áreas de terrafirme das margens do rio. Vinham do Baixo em busca de espaços que apresentassem possibilidades para uma vida melhor do que nos seus locais de origem: "viemos porque lá ficou uma situação difícil de sobreviver, muita gente, dificuldade muito grande, não tinha completamente alimentação, só tinha que ir para o "braço da balança" (compra), mais do que se arrumar da alta floresta e da juquira”. (Antonino, homem com 60 anos). Dos entrevistados, quatro pessoas que chegaram ainda crianças, vindos dos igarapés Nauerá, Maracaxi, Pirajauara e Caratateua, no Baixo Capim e alcançaram o Alto em um processo gradativo de subida do rio. Moraram antes em pelo menos dois outros lugares, conheceram melhor o Alto e acabaram se casando com parentes de Salazar. Se estabeleceram e, em alguns casos, acabaram trazendo mais alguns membros da família ${ }^{5}$.

\section{De 1935 a 1975 - Extração de Madeira Branca em Prancha}

A madeira em prancha, tirada no serrotão, era entregue aos "patrões" que exerciam grande poder sobre os comunitários por serem praticamente o único meio de contato com o centro urbano e permitirem a troca dos produtos da floresta pelos da cidade. ${ }^{6}$ McGrath (1999) ressalta que, para os que moravam no interior e tinham dificuldades de transporte, o endividamento com o "patrão" chegava a ser até uma forma de segurança, uma maneira de construir a continuidade nos

\footnotetext{
${ }^{2}$ Alto é um termo recorrente no vocabulário dos caboclos do Capim. Serve principalmente para fazer diferença de quem veio ou vem do Baixo, embora os limites entre Alto e Baixo não estejam bem definidos. Antes de serem termos que expressem divisão clara, eles servem para indicar movimentos, pois ou se vai do Alto para o Baixo ou o contrário. Em seus diálogos não existe o M édio Capim. Adotaremos a divisão local referindo-nos sempre como sendo Alto Capim as áreas onde está a comunidade e área mais acima, de onde tiraram madeira.

${ }^{3}$ Serrote grande manuseado por duas pessoas que foi a ferramenta mais usada pelos serradores de madeira em prancha.

${ }^{4}$ É uma embarcação com espaço para 12 pessoas movida a partir de remos característicos, chamados remos de faia. É diferente da montaria (canoa), embarcação para, no máximo, 5 pessoas.

${ }^{5}$ Aragón (1986), discutindo o processo migratório na América Latina, demonstra a importância das redes de parentesco nas estratégias de migração. Segundo o autor, a estratégia dos migrantes mantém ativas a comunicação e a ajuda mútua entre os membros de um mesmo grupo familiar, estabelecendo um certo tipo de campo de informação a partir de um lugar de referência. Aragon (apud. Le Play) argumenta que as famílias migrantes deixam alguns membros tomando conta de uma base geográfica e enviam outros para tentar a sorte em outro lugar; se estes membros obtêm êxito, a família toda se move para o novo lugar; se não, os pioneiros retornam à base e o processo se repete por gerações.

${ }^{6}$ Santos (1989) revela a importância do aviamento como viabilizador do aparecimento e permanência do campesinato amazônico, "o campesinato nasceu e se desenvolveu tendo como mediadores o "aviamento"e a abundância física de terra, e esteve situado tensamente entre dois pólos: a liberdade e a espoliação" (Santos, 1989: 51).
} 


\section{ACTA \\ AMAZONICA}

OCUPAÇÃO CABOCLA E EXTRATIVISMO MADEIREIRO

NO ALTO CAPIM: UMA ESTRATÉGIA DE REPRODUÇÃO CAMPONESA intercâmbios. As dívidas eram comuns e os extratores se viam obrigados a subir o rio para tirar a madeira e pagar a dívida e, caso não conseguissem, precisavam voltar no outro ano, sob pena de perder o crédito e ser-lhe tomado o serrotão.

Neste tempo, o rancho trazido pelo patrão era essencial para garantir o acesso a alguns produtos que as famílias do Capim não produziam ou mesmo consideravam mais vantajoso que fossem trazidos de fora. A variedade dos produtos adquiridos do mercado aumentou, pois embora a coleta de produtos florestais (principalmente de caça) fosse grande, pouco trabalho estava sendo dedicado à agricultura. As atividades de agricultura perderam importância porque as famílias conseguiam com a madeira uma melhor remuneração para seu esforço de trabalho.

Este foi o período áureo da extração de madeira serrada no Alto Capim. Como garantisse o sustento das famílias através da troca pelo rancho, a madeira se tornou a principal atividade a ocupar a mão-de-obra local. Além da madeira, eram negociados com os patrões o látex da maçaranduba e couros de animais silvestres, mas estes produtos tiveram seu mercado reduzido a partir de $1960^{7}$. Também eram utilizados e negociados com os marreteiros óleo de copaíba (Copaifera spp.), cipó-titica (Heteropisis flexuosa), breu (Protium sp.), jutaicica (resida da árvore de jatobá, Hymeneae coubaril) e varas de madeira (várias espécies). Até hoje, é possível vender estes produtos com relativa facilidade, porém, como no passado, quando as vendas acontecem, a quantidade negociada dos produtos é pequena. A madeira, por outro lado, tinha a vantagem de ter um valor de troca considerado alto e uma demanda constante de um comércio dificilmente saturável.

\section{De 1975 a 1983 - Madeira Branca em Rolo}

No Quiandeua, as mudanças causadas pela construção da Rodovia Belém-Brasília só começaram a ser percebidas a partir da década de 1970 , quando a extração de madeira em prancha perdeu competitividade depois da chegada das serrarias e do loteamento das áreas que serviam como fonte de madeira. Como alternativa, as famílias começaram a procurar áreas não loteadas mais próximas à comunidade para extrair madeira em rolos $^{8}$ e vender para duas serrarias pequenas que haviam se instalado nas proximidades. As madeiras brancas eram as preferidas pois, por serem menos densas, podiam ser transportadas para os rios e dali saírem boiando. Quando madeiras mais densas e com grande valor de mercado eram encontradas próximas aos fluxos d'agua, eram amarradas aos rolos de madeira branca para serem transportadas. Espécies como virola (Virola sp.), faveira (Parkya sp.), freijó (Cordia spp.), breu (Protium sp.), amapá (Brosimum parinarioides), pará-pará (Jacaranda copaia), morototó (Schefflera morototoni), timborana (Albizia sp.), e pau d'arco (Tabebuia sp.) foram as mais procuradas.

Neste tempo, formavam-se grupos de 3 a 5 moradores e cada grupo extraía no mínimo 50 rolos a cada ano. A madeira era retirada no inverno e os extratores trabalhavam no máximo 3 meses por ano, "mas o serviço era puxado para aproveitar a cheia". O acesso aos recuros florestais era livre. Valia a lei: "trabalhou, tem o direito de levar". Neste período, instauraramse novas formas de negociação e o sistema de aviamento de rancho para os extratores caiu. A madeira em rolo do Alto Capim passou a ser negociada ou com os donos de serrarias ou com intermediadores (que revendiam para as serrarias) e o pagamento passou a ser em dinheiro. Mas, na maior parte dos casos, os extratores trabalharam subordinados aos donos das serrarias, que financiavam as extrações e, portanto, possuíam controle do processo e sobre seu produto - a madeira.

Com a maior proximidade com o comércio e uma vida social crescendo proporcionalmente ao aumento do número de moradores, passou a ser maior a demanda das famílias por produtos provenientes da cidade. Neste período, o extrativismo passou a ser importante para complementar a economia familiar. A quantidade e variedade de produtos de subsistência provenientes do comércio aumentou: café, açúcar, sabão, óleo, carne, arroz e feijão. Ainda era fácil conseguir peixe no rio, mas a caça já havia diminuído consideravelmente, provavelmente por causa dos desmatamentos provocados pelas fazendas que já cercavam a comunidade. ${ }^{9}$

A maior dedicação ao extrativismo da madeira em rolo durou até a redução da quantidade de árvores mais próximas aos cursos d'agua, por volta de 1983. Junto com a redução dos recursos, a chegada dos primeiros madeireiros, que se responsabilizavam pela retirada da madeira, marca o fim da extração da madeira em rolo e o início da exploração em terra-firme.

\section{Parte 2 - de 1983 a 2002 - Madeira Vermelha da Terra Firme}

O rápido e recente crescimento da indústria madeireira na Amazônia e a liderança do Pará neste processo são dignos de nota. Metade das empresas madeireiras do Pará iniciou suas atividades na década de 1990,39\% se estabeleceram na década

\footnotetext{
${ }^{7}$ Por volta de 1960, com a queda no preço e a adulteração do produto por parte dos extratores, ocorreu o fim da extração de látex no Q uiandeua e proximidades. 0 comércio de couros, por sua vez, aconteceu em grande quantidade somente até 0 ano de 1967, quando 0 governo editou a lei n 5197 proibindo o abate de animais silvestres e a comercialização do couro.

${ }^{8} \mathrm{~A}$ árvore era derrubada e o tronco dividido perpendicularmente, geralmente em duas toras menores, formando os rolos. Esta técnica facilitava o arraste da madeira para os cursos d'agua. O s rolos eram transportados sobre a "lagarta", uma construção de varas amarradas com cipós que, tracionada pelos caboclos, desliza por uma trilha previamente preparada com varetas roliças.

${ }^{9} \mathrm{~N}$ a segunda metade da década de 1970, os fazendeiros começaram a se estabelecer na vizinhança e a derrubar grandes áreas de floresta. Sua chegada implicava perdas para os caboclos, principalmente porque muitas áreas de caça estavam sendo transformadas em pasto. Em contrapartida, a derrubada da mata das fazendas ofereceu uma oportunidade de trabalho sazonal para alguns caboclos locais.
} 


\section{ACTA AMAZONICA}

de 1980 e apenas $11 \%$ foram instaladas durante os anos 70 ou antes (Veríssimo et al. 2002). A exploração madeireira, no entanto, tem se dado de forma predatória e sua economia tem seguido o modelo crescimento-colapso (Veríssimo et al., 2002). Segundo o modelo, depois de um rápido crescimento na primeira década, por volta do vigésimo ano de extração ocorre a escassez de madeiras de valor comercial e a economia local entra em crise (Schneider et al. 2000).

A extração da madeira de acordo com este modelo predatório leva a um processo de migração constante das empresas madeireiras em busca de novas áreas para explorar. O trabalho de Souza Jr. et al. (2000) mostra que 73\% do Estado do Pará é coberto por florestas que, em sua maior parte (77\%), são economicamente acessíveis à atividade madeireira. ${ }^{10}$

No Quiandeua, esta expansão da atividade madeireira começou a ser percebida no início da década de 1980, quando os madeireiros alcançam o Alto e passam a negociar com comunidades e fazendeiros a compra dos direitos de exploração da madeira de suas florestas. Para as comunidades, depois da escassez das fontes de madeira branca, os madeireiros representaram novas possibilidades para a obtenção de recursos com a venda de madeira e para o estabelecimento de relações com grupos de maior poder econômico.

A extração passou a se dar em áreas de terra-firme que são mais ricas em diversidade de espécies e onde há predominância das chamadas madeiras duras, ou vermelhas, mais valorizadas no mercado. A madeira passou a ser transportada em caminhões e balsas. Os primeiros a chegar foram os madeireiros pequenos que revendiam as toras para serrarias rio abaixo e atuaram em quatro extrações dos anos de 1983 a $1990 .{ }^{11}$ Só a partir da década de 1990, empresas grandes, vindas de Paragominas, Ipixuna e Tomé-açu, alcançaram o Alto Capim.

Dentre os madeireiros grandes (que exploraram a área a partir de 1990), é possível diferenciar aqueles que realizaram explorações seletivas (quatro empresas, que atuaram de 1990 a 1995) daqueles que exploraram de forma predatória (cinco empresas, que atuaram de 1997 a 2003), explorando uma variedade crescente de espécies com diâmetros de árvores cada vez maiores. Com as explorações seletivas o número de espécies e a quantidade de árvores derrubadas haviam sido relativamente pequenos. Como resultado, o consumo de PFNM ainda era consideravelmente alto. A pesquisa de Shanley (2000) mostra que a média de consumo de PFNM pelas 30 famílias da comunidade era bastante significativa. Em 1994, o consumo médio de cipós por família foi de mais de 20 quilos, o de frutas mais de 400 quilos e o de caça mais de 130 quilos.

A continuidade das extrações mesmo depois de tantos eventos de venda da madeira, é explicada por três fatores. O primeiro, conforme já havia constatado Veríssimo et al. (1996), se deve à tendência de aumento, em áreas de fronteira mais antiga, da quantidade de espécies de interesse comercial. O segundo refere-se ao fato de que árvores de diâmetro cada vez menor passaram a ser procuradas pelos madeireiros. Além disso, no Quiandeua, como as explorações não se concentraram em um só ponto, a maior parte da área havia sido explorada uma única vez. O levantamento de Veríssimo et al. (1996) é bem ilustrativo também no sentido de mostrar que mesmo depois de vários danos com a extração madeireira, uma área de floresta ainda apresenta grande potencial para futuras explorações. ${ }^{12}$

Nas explorações consideradas predatórias, uma das conseqüências foi um incêndio acidental em 1997 em mais de 500 hectares de área recém explorada. ${ }^{13}$ Decorrente dos efeitos da extração madeireira associados aos efeitos desastrosos da queimada, o consumo de PFNM pelas famílias da comunidade diminuiu significativamente tanto por sua menor oferta como pelo menor acesso aos recursos restantes. Discutindo a existência de um ponto limite até onde as florestas são capazes de resistir à exploração madeireira e continuar sendo fonte de PFNM, Shanley et al. (2002) mostram que, para o Quiandeua e duas comunidades vizinhas este ponto pode ser identificado no ano de 1997. Entre 1993 e 2003 , por exemplo, ocorreu uma queda de $80 \%$ no consumo médio da fruta do piquiá (Caryocar villosum) pelas famílias das comunidades (Shanley, P. \& Medina, G., 2004). Neste sentido, pode-se afirmar que, a partir de 1997, passa a existir um claro conflito de uso entre os produtos madeireiros e os não madeireiros. A figura 1 mostra a evolução da área e do número de espécies exploradas na comunidade.

Nas formas de negociação com os madeireiros pequenos, as relações se mantiveram bastante personalizadas. Mesmo com alguns madeireiros grandes as amizades e a troca de favores ainda estiveram presentes em alguns momentos. No entanto, com a chegada das grandes empresas, foi cada vez maior a despersonalização das relações entre a comunidade e os compradores. Não obstante, os caboclos do Capim permanecem subjugados por um mecanismo que, nos resultados alcançados, não se

\footnotetext{
${ }^{10}$ Para os próximos anos, o G overno Federal planeja reestruturar e criar Eixos $\mathrm{N}$ acionais de Transporte e Desenvolvimento. 0 objetivo principal é incentivar a produção nacional e integrar interna e internacionalmente o Brasil. Segundo o Ministério do M eio Ambiente, a fronteira do desenvolvimento poderá chegar a lugares distantes e a Amazônia será diretamente impactada por quatro grandes eixos: Eixo do Arco Norte; Eixo Madeira-Amazonas; Eixo Araguaia-Tocantins e Eixo 0 este (BRASIL, 2001). Atingidas estas metas, a tendência de migração das indústrias madeireiras deve ser ainda maior e as áreas onde o acesso à madeira hoje é economicamente viável deve ultrapassar os $77 \%$.

${ }^{11}$ O s madeireiros pequenos são aqueles que trabalharam com pouco maquinário, basicamente um caminhão, uma motosserra e um barco para rebocar as jangadas. O s grandes possuem um trator skider, uma ou duas carregadeiras, uma balsa, dois a três caminhões e de três a seis motosserras e, conseqüentemente, mais capacidade para extrair maior quantidade de árvores em menor espaço de tempo.

${ }^{12}$ Em um hectare estudado, de um total de 55 árvores de DAP > $30 \mathrm{~cm}$, depois da exploração ainda sobravam 60\% com uso atual ou potencial (Veríssimo et al., 1996).

130 estudo de Gerwing (2002), em Paragominas, mostra o processo de degradação que sofrem as áreas exploradas para a extração de madeira e N epstad

(1999) e Cochrane e Laurance (2002) alertam que a fragmentação e descaracterização da floresta aumentam consideravelmente sua susceptibilidade ao fogo.
} 


\section{ACTA \\ AMAZONICA}

OCUPAC̄̃̃ CABOCLA E EXTRATIVISMO MADEIREIRO

NO ALTO CAPIM: UMA ESTRATÉGIA DE REPRODUÇÃO CAMPONESA difere muito do sistema de aviamento em vigor anteriormente. Ocorre o aliciamento dos comunitários pelos madeireiros em um sistema que consiste no pagamento adiantado e em espécie de parte do valor negociado pela madeira. Como uma "isca", o dinheiro adiantado assegura o interesse dos comunitários na negociação. Além disso, os madeireiros buscam identificar alguém com capacidade de liderança nas comunidades para aliciar e sempre evitam os espaços de discussão abertos a todos os comunitários.

Novamente aqui, no contato com os madeireiros, podese verificar a dependência mútua entre vendedores e compradores. Os comunitários dependem dos madeireiros para que sua madeira possua valor de troca, pois eles mesmos não podem extraí-la e vendê-la (uma vez que não possuem o maquinário e treinamento necessários). Por sua vez, os madeireiros precisam da matéria prima, da força de trabalho da comunidade para ajudar na extração e de seu silêncio para garantir a extração da madeira ilegalmente. A extração de floresta não plantada é considerada legal quando a madeira é proveniente de área com autorização para o desmatamento concedida dentro do limite máximo de $20 \%$ da propriedade (M.P. 2166-67/01) ou de planos de manejo florestal sustentável aprovados pelo IBAMA (Guimarães, 2003) ${ }^{14}$. Em todos os casos de venda no Quiandeua isto não aconteceu.

Na extração da madeira vermelha, o pagamento foi feito inicialmente pela quantidade de árvores transportadas e depois por área explorada, mas o dinheiro resultante não era mais o que mantinha as famílias. De fato, o dinheiro proveniente da venda da madeira foi importante para proporcionar a aquisição de bens substitutos no mercado. Este poder de compra garantiu tanto o acesso a bens de subsistência como também a bens de consumo. O visitante que porventura entrar em algumas casas do Quiandeua onde moram as famílias com maiores posses, certamente encontrará um fogão a gás; camas compradas no mercado de Ipixuna; colchões; guarda-roupas com portas com espelhos; aparelhos de som e bicicletas. A última venda também representou a possibilidade real de tentar consertar um barco ganho da prefeitura de Ipixuna e conseguir comprar gado, coisa que não havia sido possível somente com o dinheiro da venda da farinha (principal produto agrícola comercializado).

No entanto, talvez mais que o dinheiro ou o que foi feito com ele, o que está mais vivo na memória dos entrevistados são os favores prestados pelos madeireiros. Eles construíram o barracão da igreja (que hoje não existe mais), ajudaram usando o caminhão para buscar madeira para construções na comunidade e farinha na roça, emprestaram a motossera (algumas famílias já faziam roça de motossera) e doaram combustível. A gratidão das famílias da comunidade pode ser vista neste depoimento: "ele (o

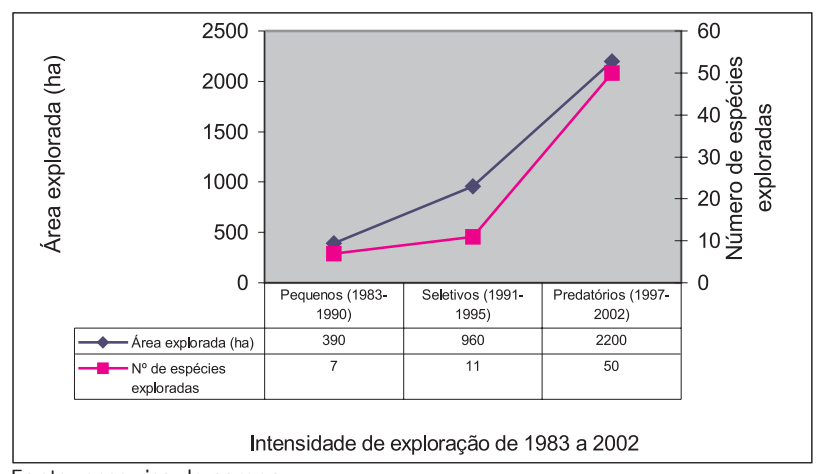

Fonte: pesquisa de campo

Figura 1 - Evolução da área e do número de espécies exploradas no Quiandeua entre 1983 e 2002.

madeireiro) não dava o coração porque não podia tirar" ("Dona" Teodora, mulher com 38 anos).

Nesta fase, mesmo que a gestão conjunta dos recursos madeireiros já estivesse definida, existiram fortes influências individuais na decisão do grupo sobre as vendas. Como comentou o coordenador da comunidade, "administrar o que é meu é fácil, mas administrar o que é nosso é difícil. Nós combinamos, não era para vender a madeira, mas também não era para colocar roça na mata, que a roça também estraga, mas no meio de todos quando quatro fazem diferente, estraga. O cara começava a fazer errado, mas se a gente fosse falar ele poderia não gostar e a gente achou melhor vender tudo logo" (Ocário, homem com 27 anos).

\section{Parte 3 - Representação Sobre os Produtos Florestais e o Contexto em que é construída}

Pode-se afirmar que, ao longo da história, a floresta representou para a comunidade do Quiandeua uma berança com valor de troca de uso não conflituoso. Herança porque utilizada ao longo do tempo conforme as necessidades e oportunidades de modo a garantir a manutenção e desenvolvimento do grupo que se estabelecia. Em comparação com outros produtos da mata, a madeira foi o único que sempre apresentou valor de troca relativamente alto. Além disso, não cabe, pelo menos até o ano de 1997, a idéia de conflito de uso entre a extração madeireira e a coleta de outros produtos para o uso local ou para venda. Representada desta forma, a venda da madeira aparece como uma possibilidade estratégica de melhoria das condições de vida das famílias da comunidade.

Esta representação, no entanto, esteve condicionada por

\footnotetext{
${ }^{14}$ Principalmente em áreas de expansão da atividade madeireira, é comum que a extração se desenvolva de forma ilícita. Não raro, os madeireiros tomam posse de terras devolutas e exploram de forma ilegal áreas indígenas e áreas protegidas e também aliciam e/ou ameaçam agricultores e comunidades. U m levantamento da organização Amigos da Terra estima que $80 \%$ da madeira produzida na Amazônia seja ilegal e, em regiões de fronteira, este índice chega a 95\% (Amigos da terra - Programa Amazônia, 1997). Tal prática tem dificultado o estabelecimento do manejo florestal. Na prática atual, o manejo florestal perde o sentido da viabilidade econômica pois seu custo efetivo é muito maior do que o da exploração não manejada (Homma, 1998).
} 


\section{ACTA AMAZONICA}

fatores contextuais que influenciaram a importância atribuída à floresta e garantiram a manutenção das vendas mesmo depois que o conflito de uso entre madeira e PFNM ficou evidente. Vejamos:

\section{As relações paternalistas}

A compreensão da Amazônia como um locus onde o moderno e o atrasado ainda se confundem é essencial para antecipar o contexto em que se dão as relações internas entre os membros da comunidade e suas relações com o meio externo. Mesmo que o avanço das empresas madeireiras sobre novas áreas marque a chegada de uma frente econômica modernizadora, ou da frente pioneira, de que fala Martins (1997), esta modernização não é pressuposto, como ressalta o próprio autor, de uma tendência linear e radicalmente compulsória à racionalização da vida social, seu desencantamento e sua tendência evolutiva na direção da individualização das pessoas e do predomínio de relações sociais de tipo contratual. Se as relações na Amazônia se modernizaram, foi apenas superficialmente (Brito, 2001) ${ }^{15}$.

Do ponto de vista das estratégias camponesas de sobrevivência neste contexto, vale atentar para a observação do antropólogo James Scott (1985) sobre a importância de se conhecer melhor o que se pode chamar de formas quotidianas de resistência camponesa - uma prosaica mas constante luta entre os camponeses e aqueles que procuram lhes explorar. Scott mostra que o sucesso da resistência está freqüentemente relacionado com a conformidade simbólica que ela mascara: é preferível aos grupos mais fracos, ao invés de uma resistência aberta e sujeita a respostas mais rápidas e ferozes, uma resistência com grande difusão mas que não conteste a hierarquia formal e o poder vigente. Pierre Bourdieu (2001) mostra que o poder simbólico pode ser compreendido como invisível, só exercido com a cumplicidade daqueles que não querem saber que estão sujeitos ou mesmo que exercem sujeição. Os símbolos seriam, então, instrumentos da integração social, pois, como instrumentos de conhecimento e de comunicação, tornariam possível o consensus sobre o sentido do mundo (Bourdieu, 2001). Isto teria, por sua vez, papel fundamental na reprodução da ordem social.

No Capim, principalmente nas primeiras fases do histórico, as posições ocupadas no campo social pelos compradores de madeira e pela comunidade eram muito próximas. Existia entre os atores uma vida em comum e, independentemente do processo de exploração que os ligava, relações de efetiva amizade se estabeleceram entre as partes.

Dentro deste campo, a principal "arma" empunhada pelas famílias do Quiandeua foi a elaboração e a manutenção de relações paternalistas com os compradores de madeira. Se a metáfora paternal - do comprador visto como um pai amigo da comunidade - (Picard, 1998) for concebida como uma possibilidade de forjar uma relação na qual o "pai" não assume premeditadamente o papel de explorar o outro e, se dentro do contexto em que a exploração acontece, possam estar presentes também traços de legítima amizade e confiança entre as partes, pode-se dizer que a história das relações sociais que envolve a exploração madeireira no Alto Capim está recheada da metáfora paternal. Mais ainda, pode-se afirmar que o caráter paternalista das relações foi fundamental para sua continuidade ao longo do tempo.

Neste sentido, mais que a figura do comprador que dá valor de troca à madeira ${ }^{16}$ era importante para as famílias que este comprador também oferecesse, como um pai o faria, algumas facilidades. Com pouco poder de barganha para negociar um preço mais alto para sua madeira, em alguns casos, o interesse do grupo estava mais concentrado em tirar vantagens das condições que a presença dos compradores poderia oferecer. Do rancho aviado pelos compradores de madeira em prancha ao óleo para fazer funcionar o motor, passando pelo caminhão emprestado para transportar produtos da roça, os campos de futebol, a madeira para as casas, todos são benefícios dos quais a comunidade só pôde dispor quando existiram madeireiros trabalhando em sua área. Mesmo as caronas cedidas pelos madeireiros são sempre encaradas como um favor, um privilégio concedido e, mesmo que o transporte fosse pago, continuaria sendo motivo de gratidão pois o madeireiro, a princípio, não está ali para prestar este serviço.

A elaboração destas formas de relação personalizadas permitiu que atitudes violentas, recorrentes em áreas de fronteira, não tenham sido registradano Capim. Aqui como sugere Scott (1985), mais do que em conflitos explícitos,o aspecto trágico da degradação do outro de que fala Martins (1997) será mais facilmente encontrado nas formas de relacionamento caracteristicamente amistosas entre os cablocos e os compradores de madeira.

\section{Dificuldades na Gestão Comum dos Recursos}

A teoria de tragédia dos comuns, apresentada por Hardin (1968) tem sido criticada em muitos aspectos mas um de seus méritos foi o de ter chamado a atenção para o fato de que, no estudo de um grupo, é importante atentar para a existência de interesses particulares que podem não estar em consonância com os interesses dos demais.

\footnotetext{
${ }^{15}$ N este caso, no mínimo se está diante de uma certa lentidão do processo histórico que avança sob o jugo do "poder do atraso" (Martins, 1999). Como mostra Martins (1998), é recorrente na história brasileira a produção capitalista de relações não capitalistas.

${ }^{16} \mathrm{~N}$ o Histórico, a experiência frustrada da comunidade tentando vender madeira por contra própria mostra que, mesmo que o recurso madeireiro existisse e possuísse valor de troca no mercado, este valor só pôde ser realizado quando as famílias contaram com a presença de figuras externas à comunidade (os compradores).
} 


\section{ACTA \\ AMAZONICA}

OCUPAC̄̃̃ CABOCLA E EXTRATVISMO MADEIREIRO

NO ALTO CAPIM: UMA ESTRATÉGIA DE REPRODUÇÃO CAMPONESA
Na primeira parte do histórico do Quiandeua, a madeira era vista como de livre acesso àqueles que estivessem dispostos a trabalhar em sua extração. No Quiandeua, algumas famílias, com maior habilidade no manejo da motossera, ou com mais facilidade para negociar com os compradores tiraram maior vantagem da exploração dos recursos. Na segunda parte do histórico a madeira passou a pertencer a todos os membros da comunidade e cada decisão de venda passou a ser feita em conjunto.

Mas a posse comum dos recursos não significa necessariamente acesso e controle equitativo dentro do grupo. Brinkiman et al. (1991) ressaltam que, considerando o sistema de posse como sujeito ao processo social, estudos empíricos têm demonstrado que os sistemas de manejo comum sofrem influências e estão sujeitos a pressões internas e externas ao grupo. É comum que indivíduos tenham interesses conflitantes com o interesse do conjunto e também não é raro que indivíduos mais influentes tirem vantagem sobre os demais (Brinkiman et al. 1991).

No histórico do Quiandeua, só a partir do momento em que a madeira passou a ser de interesse de todos é que foi considerado que o dinheiro proveniente de sua venda deveria ser repartido. Mas mesmo com esta igualdade de direitos, nas vendas seguintes, o interesse de algumas famílias se sobrepôs ao de outras. A partir do momento em que a madeira passou a ser vista como bem de propriedade comum, a sua forma de gestão passou a estar sujeira a pressões de indivíduos que não estavam necessariamente afinados com o interesse do conjunto (se é que se pode falar de um interesse comum). A frase do coordenador da comunidade dizendo que "administrar o que é meu é fácil, mas administrar o que é nosso é difícil", junto com o exemplo de um comunitário que levou a família para a cidade e passou a promover a venda de madeira junto à comunidade são bem esclarecedores. Desta forma, podese afirmar que as dificuldades na gestão comum dos recursos exerceram forte influência na decisão da comunidade em relação à venda da madeira.

\section{Especialização e Dependência do Mercado}

A afirmação de Santos (1989) de que, diferentemente do campesinato clássico, o camponês amazônico não está apto para a produção de vários artigos de que tem necessidade, encontra respaldo nos dados empíricos da reconstrução do histórico do Quiandeua. De fato, desde o início, a ocupação da área esteve vinculada ao rancho aviado pelo patrão às famílias extratoras de madeira. A madeira foi sempre essencial para garantir às famílias o acesso aos produtos do mercado de que precisavam.
Além disso, o modelo teórico elaborado por Wilkie e Godoy (1996) chama a atenção para a tendência de que a crescente integração da comunidade no mercado gere sua especialização em atividades com alto valor de troca no mercado que permitem a importação de produtos substitutos a muitos que a comunidade antes produzia.

No Capim, a madeira funcionou como este produto capaz de render o suficiente para que as famílias perdessem seu interesse pelos outros, substituídos por bens de mercado. No histórico do Quiandeua, com a morte de Salazar e à medida em que os homens começaram a subir o rio para tirar madeira, a roça e outras atividades extrativas, com grande importância no emprego da força de trabalho do grupo, foram perdendo espaço. A madeira tornou-se, então, a principal atividade a ocupar o tempo e a força de trabalho do grupo e praticamente só as mulheres e crianças ficam para tomar conta da roça.

No caso do Capim é importante considerar que os ganhos obtidos com o extrativismo da madeira eram suficientes para oferecer às famílias o acesso aos produtos de mercado de que precisavam, garantindo sua reprodução. Além disso, a relação ganho/esforço mais alta no extrativismo madeireiro do que na agricultura mostra que um esforço extra na produção de farinha para a venda pareceu menos vantajoso do que a espera pelo começo do ano seguinte para conseguir um rendimento de trabalho bem maior com o extrativismo da madeira ${ }^{17}$. Desta forma, os produtos adquiridos do mercado estão sempre presentes ao longo do histórico da comunidade.

\section{O Fetiche do Mercado}

Santos (1989, apud Burger e Kitamura) observa que a integração na economia de mercado e a influência da cultura urbana estimulam uma demanda crescente dos agricultores, seja por produtos que antes eram obtidos da floresta, seja por alimentos produzidos internamente, mas sem possibilidade de armazenamento. Derivado do mesmo projeto do trabalho de Wikie e Godoy (1996), o livro de Demmer e Overman (2001:219) também sugere que com a maior integração da economia local no mercado, "o atrativo por produtos modernos impõe um forte esforço para que se consiga o dinheiro necessário para sua aquisição".

No Quiandeua, com o passar dos anos, foi crescente a dependência dos caboclos em relação ao mercado como forma de suprir a necessidade de produtos para o consumo local. Mas daí não se pode concluir que sua única demanda fosse por bens de subsistência. Além de ajudar em sua manutenção, o dinheiro da venda da madeira foi também importante para as famílias da comunidade por dois motivos: 1) garantiu a possibilidade de adquirirem bens aos

\footnotetext{
${ }^{17}$ Chayanov (1991) mostra que a unidade econômica familiar tem um comportamento próprio que não pode ser compreendido a partir de categorias econômicas tradicionais. 0 autor defende que o dispêndio do trabalho familiar é fortemente influenciado pelo grau de auto-exploração do trabalho, que, por sua vez, depende do equilíbrio entre a satisfação da demanda familiar e a penosidade do trabalho. Neste sentido, a economia familiar buscaria utilizar sua mão-de-obra nas atividades que prometem o mais elevado rendimento possível por unidade de trabalho.
} 


\section{ACTA \\ AMAZONICA}

quais normalmente não teriam acesso devido a seu pequeno poder de compra e, 2) possibilitou acesso a bens que representavam sonhos de consumo. Enfim, com a evolução do histórico, o dinheiro passa a circular mais facilmente e a venda da madeira é essencial como fonte.

\section{CONCLUSÃO}

Os valores e atitudes locais sobre os recursos da floresta tropical contrastam enormemente com as visões globais. Para os grupos locais, o valor dos produtos florestais é dependente da forma como são representados e do contexto em que esta representação é construída. Neste sentido, "estimar valores não é tão importante quanto interpretá-los dentro de contextos específicos" (Luckert e Campbell, 2002: 234).

No histórico do Quiandeua, o modo como a madeira foi representada pelas famílias, como uma berança com valor de troca e uso não conflituoso, foi imprescindível para que a sua exploração fosse assumida como uma possibilidade estratégica de melhoria de suas condições de vida. Imersa na idéia de ter um produto (madeira) com valor de troca e que sua exploração, pelo menos a princípio, não representasse prejuízo ao consumo dos demais produtos florestais, o extrativismo madeireiro no Alto do Rio Capim se fundamentou como uma excelente alternativa de uso da herança que a mata representava.

Mas só esta representação não explica a continuidade das vendas, principalmente a partir de 1997, quando o consumo de PFNM caiu drasticamente, expondo o conflito de uso entre a exploração da floresta para a extração comercial de madeira e o consumo de PFNM. O contexto em que a comunidade estava inserida evidenciou quatro fatores que complementam a explicação: 1) a inserção do grupo em relações paternalistas, que uniu a comunidade aos compradores, criou um clima de igualdade nas relações, onde as duas partes foram representadas como aliadas; 2) a dificuldade de gestão comum dos recursos foi determinante para desestruturar o grupo e permitir que interesses individuais exercessem influência preponderante; 3) a crescente especialização no extrativismo da madeira e conseqüente dependência do mercado, forçou cada vez mais a continuidade da atividade capaz de garantir o acesso a substitutos vindos do mercado - a extração de madeira, e por último; 4) o interesse das famílias em participar de uma economia de mercado e de todas as vantagens que ela pode oferecer completa o pano de fundo que induziu o grupo a dar continuidade à extração ao longo do histórico.

Partindo-se de como os recursos florestais são representados e dos fatores contextuais que influenciaram em sua representação, o valor atribuído a eles pela comunidade passa a ser visto como um valor relativo, isto é, um valor que não pode ser compreendido a partir de categorias convencionais de avaliação (valor econômico, de bem-estar e ecológico).
Esta conclusão de forma alguma desqualifica a discussão que se faz sobre o papel do extrativismo no desenvolvimento regional. Quando se pensa, por exemplo, em políticas públicas para a Amazônia é fundamental a reflexão sobre a viabilidade econômica, social e ecológica do extrativismo presente nos trabalhos de Homma (1993) e Alegretti (1994). A tese defendida aqui é a de que para as comunidades que detêm estes recursos, sua valorização é um fenômeno complexo e sujeito a várias condicionantes. Para compreender as decisões das comunidades é essencial conceber a importância dos produtos florestais dentro do contexto em que é construída.

\section{AGRADECIMENTO}

Agradeço a Patricia Shanley (Botânica trabalhando no CIFOR - Centro para a Pesquisa Florestal Internacional) que me orientou no desenvolvimento desta pesquisa.

\section{BIBLIOGRAFIA CITADA}

Allegretti, M. H. 1994. Políticas Para o Uso dos Recursos Naturais Renováveis: a Região Amazônica e as Atividades Extrativas. In: Clüsener-Godt, M. and Sachs, I. (Eds.). Extrativismo na Amazônia Brasileira: Perspectivas Sobre o Desenvolvimento Regional. Paris: Compêncio MAB 18UNESCO. p. 10-25

Amigos da Terra - Programa Amazônia. 1997. Relatório Atualizado Sobre Extração Ilegal de Madeira na Amazônia Brasileira: garimpagem florestal. Síntese: São Paulo. 50 p.

Aragón L.E. 1986. Uso Potencial das Redes de Parentesco como Alternativa Metodológica Para o Estudo da Migração. In: Aragón, Luís.E. e Mougeot, Luc. J.A.(orgs.). Migrações Internas na Amazônia: contribuições teóricas e metodológicas. Belém: UFPA/NAEA/CNPq. p. 15-27

Arnold, J.E.M. 1998. Managing Forests as Common Property. (FAO Forestry Parer 136) Rome: FAO. 67p.

Bourdieu, P. 2001. O Poder Simbólico. 4 ed. Rio de Janeiro: Bertrand Brasil. p. 7-16.

BRASIL. 2001. Ministério do Meio Ambiente. Avaliação e Identificação de Ações Prioritárias para a Conservação, Utilização Sustentável e Repartição de Benefícios da Biodiversidade na Amazônia Brasileira. Brasília: MMA/SBF.

Brinkman, W.; Browder, R.; Duijil, E. Van; Gerritsen, R.P. den H.; Lierop, P. van, Mol, P.; Remmers, G., Strijker, B. 1991. Communal Management of Forest Lands. BOS NiEuWSLETTER no.22, vol.10 (1), april.

Brito, D.C. 2001. A Modernização da Superfície: Estado e Desenvolvimento na Amazônia. Belém: UFPA/NAEA. 266 p.

Chayanov, A. 1991. Sobre a Teoria dos Sistemas Econômicos Não Capitalistas. In: Silvia e Stolcke (Orgs). A Questão Agrária. São Paulo: Brasiliense. p.133-147.

Cochrane, M.A.; Laurence, W.F. 2002. Fire as a Large-Scale Edge Effect in Amazonian Forests. Journal of Tropical Ecology 18:311-325. 


\section{ACTA AMAZONICA}

OCUPAÇÃO CABOCLA E EXTRATIVISMO MADEIREIRO

NO ALTO CAPIM: UMA ESTRATÉGIA DE REPRODUÇÃO CAMPONESA
Demmer J.; Overman, H. 2001. Indigenous People Conserving the Rain Forest? The Efect of Wealth and Markets on the Economic Behaviour of Tawahka Amerindians in Honduras. Wageningen: Tropenbos International (Tropenbos Series; 19). 382 p.

Derenji, J. S. 1994. A Seleção e a Exclusão no Meio Urbano: Reformas no Fim do século XIX em Belém do Pará. In: D’incao, M.A. e Silveira, I.M. da (orgs.). A Amazônia e a Crise da Modernização. Belém: MPEG. p. 256-270

Gerwing, J. J. 2002. Degradation of forests through logging and fire in the eastern Brazilian Amazon. Forest Ecology and Management 157:131-141.

Godelier, M. 1984. L'Idéel et le Matériel. Paris: Fayard. 348p.

Guimarães, N.M.S. 2003. Influência da Legislação do Manejo dos Recursos Madeireiros nas Florestas da Amazônia Brasileira. (dissertação de mestrado). Belém: UFRA.

Hardin, G. 1968. The Tragedy of the Commons. Science 162:1243-1248.

Henkemans, A.B. 2001. Tranquilidad and Hardship in the Forest: Livelihoods and Perceptions of Camba Forest Dwellers in the Northern Bolivian Amazon. Riberalta: PROMAB (Scientific Series 5). p. 1-42

Homma, A.K.O. 1993. Extrativismo Vegetal na Amazônia: Limites e Oportunidades. Brasília: Embrapa-SPI. 202p.

Homma, A.K.O.; Conto, A.J.; Ferreira, C.A.P.; Carvalho, R. de A. e Walker, R.T. 1998. A Dinâmica da Extração Madeireira no Estado do Pará. In: Homma, A.K.O. (ed.). Amazônia: Meio Ambiente e Desenvolvimento Agrícola. Brasília: Embrapa-SPI; Belém: Embrapa-CPATU. p. 161-186

Luckert, M.K. e Campbell, B.M. 2002. Expanding Our Conceptual and Methodological Understanding of the Role of Trees and Forests in Rural Livelihoods. In: Campbell, B.M. e Luckert, M.K. (ed.). Undercovering the Hidden Harvest: Valuation Methods for Woodland and Forest Resources (People and plants conservation manuals). London: Earthscan Publications Ltd. p. 228-238

Martins, J.S. 1997. Fronteira: A Degradação do Outro nos Confins do Humano. São Paulo: Hucitec. p. 145-203

1998. O Cativeiro da Terra. $7^{\mathrm{a}}$. ed. São Paulo: Hucitec. 157 p.

1999. O poder do atraso: ensaios de sociologia da história lenta. 2. ed. São Paulo: Hucitec. 130 p.

Mcgrath, D. 1999. Parceiros no Crime: o Regatão e a Resistência Cabocla na Amazônia Tradicional. In: Novos Cadernos NAEA, v.2, n 2. Belém: NAEA/UFPA. p. 57-72

Nepstad, D.C.; Moreira, A. e Alencar, A.A. 1999. Flames in the Rain Forest: Origins, Impacts and Alternatives to Amazonian Fires. Brasília: The Pilot Program to Conserve the Brasilian Rain Forest. 161p.

Picard, J. 1998. Amazonie Brésilienne: Les Marchands de Rêves (Occupations de Terres, Rapports Socianse et Développement). Paris, l'Harmattan. 213 p.
Santos, R.A.O. 1989. O Genius de uma Economia: Reflexões e Propostas sobre o Desenvolvimento da Amazônia. In: Aragon, L.E. e Imbiriba, M.N.O. (orgs). Populações Humanas $e$ Desenvolvimento Amazônico. Belém: UFPA/ARNI/CELA. p.13-92

Schineider, R. R.; Arima, E.; Veríssimo, A.; Barreto, P.; Júnior, C.S. 2000. Amazônia Sustentável: Limitantes e Oportunidades para o Desenvolvimento Rural. Brasília: Banco Mundial; Belém: Imazon. 58p.

Scott, J.C. 1985. Weapons of the Weak: Everyday Forms of Peasant Resistance. Massachusetts: Yale University Press. p. 1-47

Shanley, P. 2000. As the Forest Falls: the Changing Use, Ecology and Value of Non-Timber Forest Resources for Caboclo Communities in Eastern Amazonia. PhD Dissertation. The Durrel Institute of Conservation and Ecology, the University of Kent, Canterbury, Great Britain. 214p.

Shanley, P., Luz, L.; Cymerys, M. 2002. The Interface of Timber and Non-Timber Resources: Declining Resources for Subsistence Livelihoods (Brazil). In: Shanley, P.; Pierce, A.R.; Laird, S.A.; Guillén, A. Tapping the Green Market: Management and Certification of Non-Timber Forest Products a Summary. London: Forthcoming from Eadthscan Publications Ltd. p. 313-321

Shanley, P. \& Medina, G. (Edts.) 2004. Frutíferas e Plantas Úteis na Vida Amazônica. Belém: CIFOR/Imazon. p. 233-252

Souza Jr., C.; Veríssimo, A.; Lima, E. e Salomão, R. 2001. Alcance Econômico da Exploração Madeireira na Amazônia. Belém: Imazon. 27 p.

Veríssimo, A. Barreto, P.; Mattos, M.; Tarifa, R.; Uhl, C. 1996. Impactos da Atividade Madeireira e Perspectivas para o Manejo Sustentável da Floresta Numa Velha Fronteira da Amazônia: O Caso de Paragominas. In: Barros, Ana C. e Veríssimo, Adalberto (Eds). A Expansão da Atividade Madeireira na Amazônia: Impactos e Perspectivas para o Desenvolvimentos do Setor Florestal no Pará. Belém: Imazon. p. 47-73

Veríssmo, A.; Lima, E.; Lentini, M. 2002. Pólos Madeireiros do Estado do Pará. Belém, Imazon. 72 p.

Wilkie, D.S.; Godoy, R.A. 1996.Trade, Indigenous Rain Forest Economies and Biological Diversity: Model Predictions and directions for Research. In: Péresz, M.R. and Arnold, J.E.M. Current Issues in Non-Timber Forest Products Research. Bogor, Indonesia: CIFOR. p. 83-102

\section{RECEBIDO EM 11/06/2003 \\ ACEITO EM 26/02/2004}

